\title{
Mass Spectrometric Determination of Activities and their Dependence on Temperature in Liquid Bismuth-Tin Alloys
}

\author{
G. Riekert, P. Lamparter, and S. Steeb \\ Max-Planck-Institut für Metallforschung, Institut für Werkstoffwissenschaften, \\ Stuttgart, GFR
}

(Z. Naturforsch. 31 a, $711-716$ [1976] ; received May 5, 1976)

\begin{abstract}
Liquid alloys of the Bi-Sn system have been studied to determine thermodynamic properties. Ion currents have been measured by a double-focusing mass spectrometer. The thermodynamic values were calculated by application of the monomer-dimer ratio technique and the integration technique. Special attention was paid to the correction of fragmentation effects.

Activities of both components versus composition in the temperature range from $1023 \mathrm{~K}$ to $1323 \mathrm{~K}$ and values of Gibbs energies and heats of mixing are reported as results. At $1200 \mathrm{~K}$ the species $\mathrm{Bi}_{2}, \mathrm{Bi}_{3}, \mathrm{Bi}_{4}, \mathrm{BiSn}$, and $\mathrm{Bi}_{2} \mathrm{Sn}$ were observed in the gaseous phase above the $\mathrm{Bi}_{50} \mathrm{Sn}_{50}$ alloy. The discussion shows a tendency to segregation of the liquid $\mathrm{Bi}$-Sn alloys.
\end{abstract}

\section{Introduction}

Knowledge of thermodynamic properties is very useful for investigations of liquid metals and their structures. From the thermodynamic activities as a function of composition of the liquid phase, for instance, it is possible to draw conclusions concerning atomic or molecular interactions and formation of molecules or other complex species.

The current investigation uses the "Knudsen cell - mass spectrometer" combination to determine the activity of liquid bismuth-tin alloys. Application of the corrected monomer-dimer technique ${ }^{1,2}$ and of the integration technique ${ }^{2,3}$, which are based on the measurement of ion current ratios, made the results independent of apparative factors.

\section{Theoretical Basis}

The activity $a_{\mathrm{i}}$ of component "i" is given by the ratio of the partial pressure $p_{\mathrm{i}}$ of this component above the alloy to the pressure $p_{\mathrm{i} 0}$ above the pure component " $i$ ":

$$
a_{\mathrm{i}}=p_{\mathrm{i}} / p_{\mathrm{i} 0} .
$$

Pressure measurement is reduced in the mass spectrometer to the measurement of an ion current

$$
p_{i}=k_{\mathrm{i}} I_{\mathrm{i}}^{+} T
$$

where $T=$ absolute temperature and $\mathrm{I}_{\mathrm{i}}^{+}=$measured ion current corrected for isotopic abundance

$$
k_{\mathrm{i}}=g /\left(\sigma_{\mathrm{i}} \beta_{\mathrm{i}}\right) \text {. }
$$

Here, $g=$ geometric factor, which changes from one experiment to the other, $\sigma_{\mathrm{i}}=$ ionization cross section, $\beta_{\mathrm{i}}=$ detector sensitivity.
To avoid having to determine the factor $k_{\mathrm{i}}$, the following ratio is used in the monomer-dimer method:

$$
a_{\mathrm{A}}^{+}=\frac{\left(I_{\mathrm{A}_{2}}^{+} / I_{\mathrm{A}}^{+}\right) \text {solution }}{\left(I_{\mathrm{A}_{2}}^{+} / I_{\mathrm{A}}^{+}\right) \text {pure }},
$$

$I_{\mathrm{A}_{2}}^{+}=$ion-current of the dimer $\mathrm{A}_{2}$ and $I_{\mathrm{A}}^{+}=$ion-current of the monomer $A_{1}$.

The thermodynamic activity $a_{\mathrm{A}}^{*}$ of component $\mathrm{A}$ is given by Eq. (4) if there is no fragmentation ionization in the ionization region, i. e. if no molecule coming out of the Knudsen cell is fragmented during the ionization process. If the fragmentation is not negligible, $a^{*}$ has to be corrected. In the case of a contribution of only the dimer to fragmenta. tion, the correction equation is given by ${ }^{2}$

$$
a_{\mathrm{A}}=a_{\mathrm{A}}^{*} /\left[1+K_{\mathrm{A}}\left(1-a_{\mathrm{A}}^{*}\right)\right] ;
$$

$K_{\mathrm{A}}$ is the correction factor, which according to ${ }^{2}$ is the ratio of the monomers resulting from fragmen. tation to those coming out directly from the Knudsen cell. It should be noted that this definition is only valid for the vapor above the pure component $\mathrm{A}$.

It is possible to separate the measured ion current of the monomer above the pure $\mathrm{A}$ into two

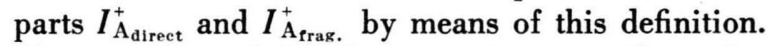
$I_{\mathrm{A}_{\text {direct }}}^{+}$is formed by direct ionization, $I_{\mathrm{A}_{\text {fras. }}}^{+}$by fragmentation.

Then it follows that

$$
I_{\mathrm{A}_{\mathrm{d} \text { reet }}}^{+}=I_{\mathrm{A}_{\text {meas. }}}^{+}\left(\frac{1}{1+K_{\mathrm{A}}}\right)
$$

and

$$
I_{\mathrm{A}_{\text {frag. }}}^{+}=I_{\mathrm{A}_{\text {meas. }}}^{+}\left(\frac{K_{\mathrm{A}}}{1+K_{\mathrm{A}}}\right) \text {. }
$$


For the second method, which has been used, namely the integration technique, the activity coefficients $\gamma_{A}$ and $\gamma_{B}$ are given by the relations:

$$
\begin{aligned}
& \ln \gamma_{\mathrm{A}}=-\int_{N_{\mathrm{A}}=1}^{N_{\mathrm{A}}} \frac{N_{\mathrm{B}}}{1+N_{\mathrm{B}}} \mathrm{d}\left\{\ln \frac{I_{\mathrm{B}}^{+} N_{\mathrm{A}}^{2}}{I_{\mathrm{A}_{2}}^{+} N_{\mathrm{B}}}\right\} \\
& \ln \gamma_{\mathrm{B}}=-\int_{N_{\mathrm{B}}=1}^{N_{\mathrm{B}}} \frac{N_{\mathrm{A}}}{1+N_{\mathrm{B}}} \mathrm{d}\left\{\ln \frac{I_{\mathrm{A}_{2}}^{+} N_{\mathrm{B}}}{I_{\mathrm{B}}^{+} N_{\mathrm{A}}^{2}}\right\}
\end{aligned}
$$

where $N_{\mathrm{A}}$ and $N_{\mathrm{B}}$ are the mole fractions of components $\mathrm{A}$ and $\mathrm{B}$, respectively, $\left(N_{\mathrm{A}}+N_{\mathrm{B}}=1\right)$.

Provided that only the $\mathrm{A}_{2}$ molecules of component $A$ contribute to fragmentation and that only $B$ atoms enter the ionization region, the differential values in Eqs. (8) and (9) are not affected by any fragmentation.

If the temperature dependence of the activities is known, further thermodynamic properties can be determined. The partial molar heat of mixing and the integral molar heat of mixing follow from Eq. (10) :

$$
\begin{aligned}
\Delta H & =N_{\mathrm{A}} \Delta H_{\mathrm{A}}+N_{\mathrm{B}} \Delta H_{\mathrm{B}} \\
& =N_{\mathrm{A}} R \frac{\mathrm{d} \ln a_{\mathrm{A}}}{\mathrm{d}(\mathrm{l} / T)}+N_{\mathrm{B}} R \frac{\mathrm{d} \ln a_{\mathrm{B}}}{\mathrm{d}(\mathrm{l} / T)} .
\end{aligned}
$$

Equation (11) permits calculation of the excess chemical potentials $\mu_{\mathrm{i}}^{\mathrm{E}}$ and the excess Gibbs free energy $\Delta G^{\mathrm{E}}$ :

$$
\begin{aligned}
\Delta G^{\mathrm{E}} & =N_{\mathrm{A}} \mu_{\mathrm{A}}^{\mathrm{E}}+N_{\mathrm{B}} \mu_{\mathrm{B}}^{\mathrm{E}} \\
& =N_{\mathrm{A}} R T \ln \gamma_{\mathrm{A}}+N_{\mathrm{B}} R T \ln \gamma_{\mathrm{B}} .
\end{aligned}
$$

\section{Experimental}

The investigation of thermodynamic equilibria of melts by Knudsen cell mass spectrometry generally includes three steps:

1. Stabilization of the thermodynamic equilibrium between vapor and liquid phase of the sample.

2. Ionization of the vapor in the ion source of the mass spectrometer.

3. Measurement of the ion current.

These three steps will be described in the following.

A double focusing mass spectrometer (MS 702, AEI, Manchester), which had to be modified considerably to meet our requirements, was used as experimental instrumentation ${ }^{4}$. The main modification was applied to the heater of the Knudsen cell, where the heating wires were replaced by a cylindrical, perforated tantalum sheet. The shutter above the Knudsen cell was modified such that it now cleans itself of coated material when moved. The current for the Knudsen cell heater was taken from a stabilized power supply. The temperature was measured by a NiCr-Ni thermocouple and a millivolt potentiometer. The arrangement was calibrated using the melting points of gold $\left(1336^{\circ} \mathrm{K}\right)$ and silver $\left(1233^{\circ} \mathrm{K}\right)$.

The cylindrical Knudsen cell (outer diameter $16 \mathrm{~mm}$, inner diameter $12 \mathrm{~mm}$, height $22 \mathrm{~mm}$ ) was made of graphite with a hole in the bottom to receive the thermocouple. Measurements of the ratio $I_{\mathrm{Bi}}^{+} / I_{\mathrm{Bi}}^{+}$were performed with an effusion orifice diameter of $0.1 \mathrm{~mm}$, that of the ratio $I_{\mathrm{Bi}_{2}}^{+} / I_{\mathrm{Sn}}^{+}$with an effusion orifice diameter of $0.25 \mathrm{~mm}$. All dimensions of the Knudsen cell were chosen with respect to the effusion relation, i. e. the following conditions had to be fulfilled:

a) The orifice diameter has to be so small that the equilibrium in the cell is not disturbed.

b) The orifice length is so small that there is no collision between molecule and surface.

c) The pressure must be low enough to avoid intermolecular collisions inside the orifice.

It was verified that the ion-current ratios were independent of the orifice diameter between the values of 0.1 and $0.25 \mathrm{~mm}$.

\section{Ionization}

The molecular beam leaving the Knudsen cell was ionized by electron impact. The energy of the ionizing electrons was varied and the ion current of the species recorded. From these ionization efficiency curves $20 \mathrm{eV}$ was found to be the best value of electron energy to investigate the Bi-Sn system.

\section{Ion-current Measurement}

The ions were accelerated by a voltage of $10 \mathrm{kV}$ and analyzed in the mass analyzer. To record the resulting ion current a multiplier and an integrator were used.

The phase diagram ${ }^{5}$ of the Bi-Sn system shows a simple eutectic system which has its eutectic point at 56 at.\% Sn and a temperature of $420^{\circ} \mathrm{K}$. Maximum solubility on the Bi-rich side is about 1 at.\%, on the Sn-rich side 13 at.\%.

The samples were prepared in an induction furnace, and 1.5 up to $3 \mathrm{~g}$ of the material was placed in the cell. To obtain a short time of measurement and, simultaneously, little composition change, measurements were performed in only one run over the whole temperature range in steps of 50 degrees.

Finally, one check measurement was made at the initial temperature. The determination of the ratio $I_{\mathrm{Bi}_{2}}^{+} / I_{\mathrm{Bi}}^{+}$was much easier than that of $I_{\mathrm{Bi}}^{+} / I_{\mathrm{Sn}}^{+}$because of the great difference between the partial pressures of $\mathrm{Bi}_{2}{ }^{418}$ and $\mathrm{Sn}^{120}$ (about $10^{6}$ at $1200^{\circ} \mathrm{K}$ ) ${ }^{6}$. To measure the very low pressures of $\mathrm{Sn}$, the effu- 
sion orifice was enlarged to $0.25 \mathrm{~mm}$ diameter. The composition change was now reduced by reducing the measurement time, i. e. the temperature range had to be small enough to get sufficient accuracy.

Finally, $I_{\mathrm{Bi}_{2}}^{+}$and $I_{\mathrm{Bi}}^{+}$were measured over a temperature range from $1000{ }^{\circ} \mathrm{K}$ to $1300{ }^{\circ} \mathrm{K}$ with a small effusion orifice, whereas for the integration evaluation $I_{\mathrm{Sn}}^{+}$and $I_{\mathrm{Bi}_{2}}^{+}$had to be measured only over 50 to 70 degrees around an average temperature of $1200^{\circ} \mathrm{K}$.

The composition was changed in steps of 0.1 over the full range. Only in the second sequence was the composition of 0.96 measured in addition to get a better determination of the integration curve.

\section{Results and Discussions}

Before starting the actual measurements, the composition of the effusing vapor was investigated by photographical ion detection. In the range from $1023{ }^{\circ} \mathrm{K}$ to $1323{ }^{\circ} \mathrm{K}$ the atoms $\mathrm{Bi}$, Sn, the molecules $\mathrm{Bi}_{2}, \mathrm{Bi}_{3}$, and $\mathrm{Bi}_{4}$, and moreover the intermetallic compounds $\mathrm{BiSn}$ and $\mathrm{Bi}_{2} \mathrm{Sn}$ could be found. This means that a tendency to segregation $\left(\mathrm{Bi}_{n}\right.$ molecules) is observed as well as a tendency to form intermetallic compounds $\left(\mathrm{Bi}_{n} \mathrm{Sn}_{m}\right.$-molecules). In this connection a recent study ${ }^{7}$ should be mentioned, where $\mathrm{Sn}_{n}$-molecules were found in this system.

Concerning the values of intensity, it has to be stated that $\mathrm{Bi}$ and $\mathrm{Bi}_{2}$ appear with ion currents which show much more intensity than those of $\mathrm{Bi}_{3}$ and $\mathrm{Bi}_{4}$, and that the $I_{\mathrm{Sn}}^{+}$values were several orders of magnitude higher than those of $I_{\mathrm{BiSn}}^{+}$and $I_{\mathrm{Bi}_{2} \mathrm{Sn}}^{+}$. For this reason only the fragmentation of the $\mathrm{Bi}_{2}$ molecules had to be taken into account.

\section{Measurement of $I_{\mathrm{Bi}_{2}}^{+} / I_{\mathrm{B}}^{+}$}

For the evaluation by the monomer-dimer meth. od, the ion currents of the ions $\mathrm{Bi}^{+209}$ and $\mathrm{Bi}_{2}{ }^{+418}$ had to be recorded as a function of temperature. From these currents the value of $\ln \left(I_{\mathrm{Bi}_{2}}^{+} / I_{\mathrm{Bi}}^{+}\right)$was calculated and plotted in Fig. 1 vs. $1 / T$. A straight line was obtained as a mean curve graphically and also numerically by the least-square method. Isothermes were obtained for the temperatures $1023^{\circ} \mathrm{K}$, $1073{ }^{\circ} \mathrm{K}, 1123{ }^{\circ} \mathrm{K}, 1173{ }^{\circ} \mathrm{K}, 1200^{\circ} \mathrm{K}, 1223^{\circ} \mathrm{K}$, $1273^{\circ} \mathrm{K}$, and $1323^{\circ} \mathrm{K}$ from the $\ln I_{\mathrm{Bi}_{2}}^{+} / I_{\mathrm{Bi}}^{+}$versus $(1 / T)$ graph. Division of the values obtained at certain concentrations by the value $I_{\mathrm{Bi}_{2}}^{+} / I_{\mathrm{Bi}}^{+}$for pure $\mathrm{Bi}$ yields according to (4) the uncorrected activity $a_{\mathrm{Bi}}^{*}$ of $\mathrm{Bi}$.

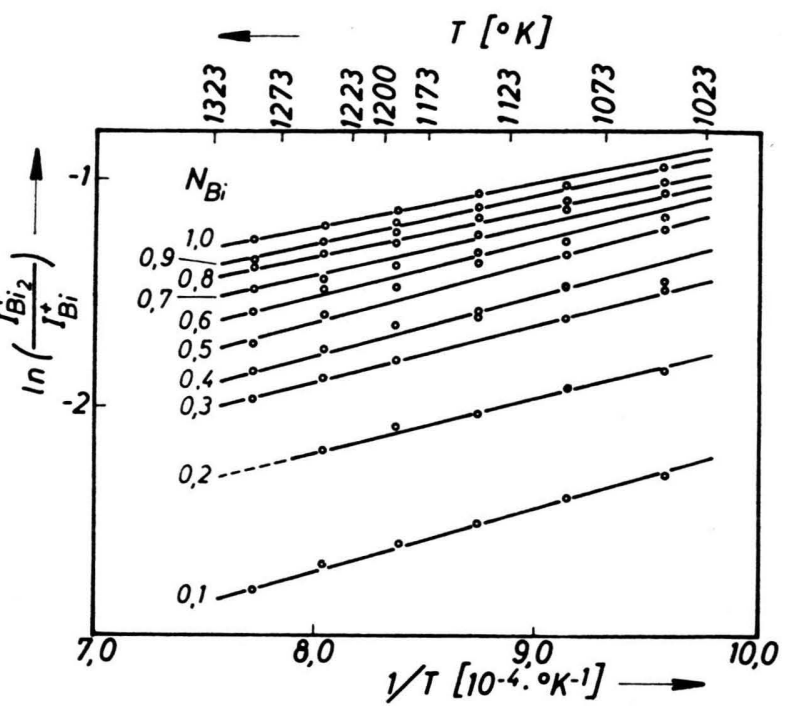

Fig. 1. Bi-Sn System : Experimental values of the ion current ratios $\ln \left(I_{\mathrm{BH}_{2}}^{+} / I_{\mathrm{B}_{1}}^{+}\right)$vs. $1 / T$.

\section{Measurement of $I_{\mathrm{Bi}_{2}}^{+} / I_{\mathrm{Sn}}^{+}$}

For these measurements the ion currents of $\mathrm{Bi}^{+209}$, $\mathrm{Bi}^{+418}$, and $\mathrm{Sn}^{+120}$ were recorded. The 120 isotope of tin was identified from the isotopic spectrum of the element tin with the aid of a plotter.

The values of $\ln \left(I_{\mathrm{Bi}_{2}}^{+} / I_{\mathrm{Sn}}^{+}\right)$were plotted vs. $1 / T$ as shown in Figure 2. As indicated in Fig. 2 by an arrow $(\downarrow)$ an isothermal section was taken at a temperature of $1200^{\circ} \mathrm{K}$.

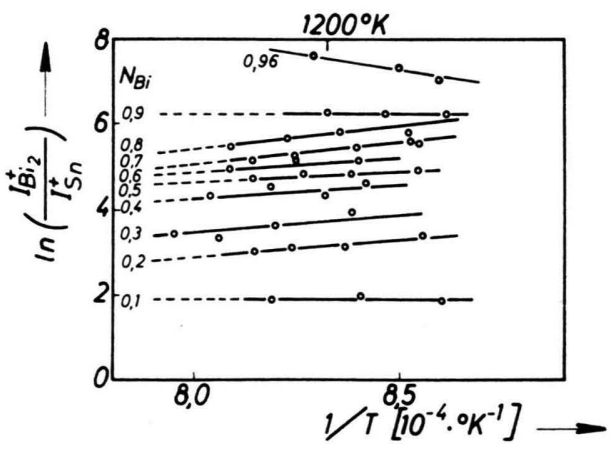

Fig. 2. Bi-Sn System: Experimental values of the ion current ratios $\ln \left(I_{\mathrm{B}_{2}}^{+} / I_{\mathrm{Sn}}^{+}\right)$vs. $1 / T$.

\section{Evaluation of Activities}

According to Eq. (8) (with $\mathrm{A}=\mathrm{Bi}$ and $\mathrm{B}=\mathrm{Sn}$ ) the values of $N_{\mathrm{Sn}} /\left(1+N_{\mathrm{Sn}}\right)$ and $N_{\mathrm{Bi}} /\left(1+N_{\mathrm{Sn}}\right)$, re- 


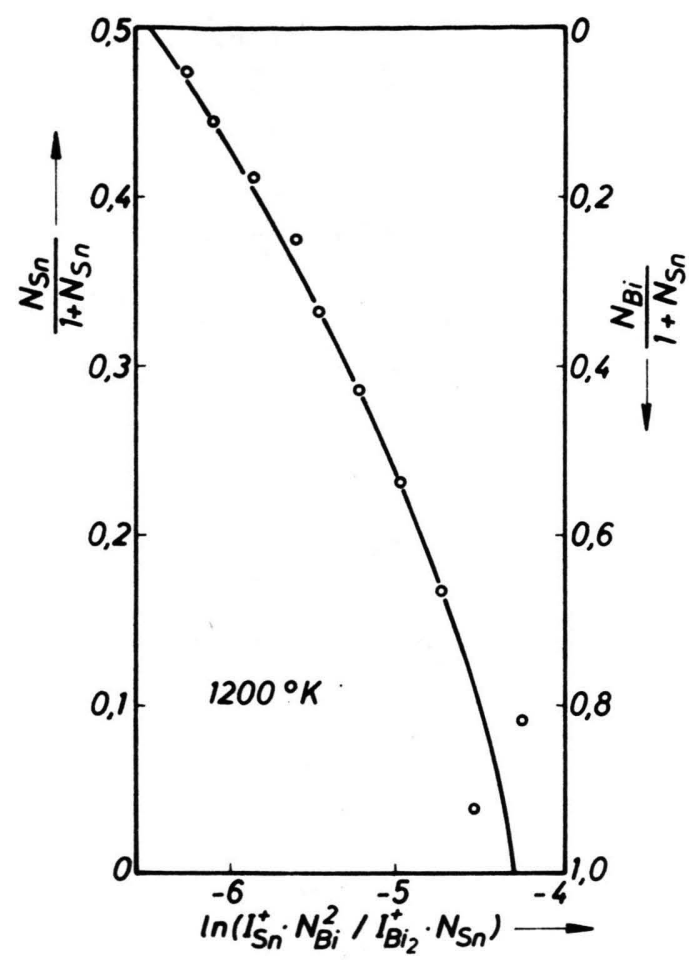

Fig. 3. Bi-Sn System: Integration plot at $1200^{\circ} \mathrm{K}$ in accordance with Equation (8).

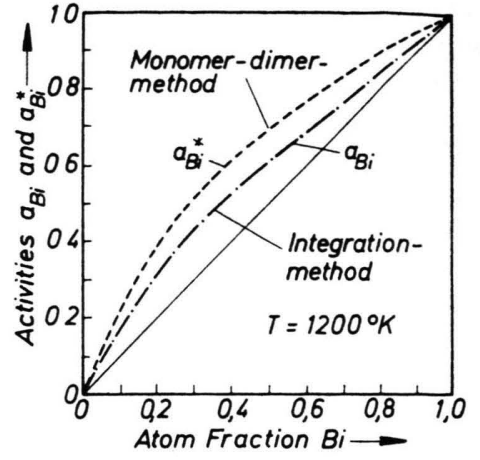

Fig. 4. Bi-Sn System: Activities $a_{\mathrm{Bi}}^{*}$ and $a_{\mathrm{Bi}}$ at $1200^{\circ} \mathrm{K}$.

spectively, were plotted versus

$$
\ln \frac{I_{\mathrm{Sn}}^{+} N_{\mathrm{Bi}}^{2}}{I_{\mathrm{Bi}_{2}}^{+} N_{\mathrm{Sn}}} \text { (see Figure 3). }
$$

From Eqs. (8) and (9) it follows that $\ln \gamma_{B i}$ is represented by the area below the integration curve, whereas the area above the curve represents $\ln \gamma_{S n}$.

The activities $a_{\mathrm{Bi}}$ obtained by numerical integration were now plotted in Fig. 4 (dotted line with points) along with the $a^{*}$ values obtained by the monomer-dimer method (dotted line) vs. molefraction of $\mathrm{Bi}$ at $1200^{\circ} \mathrm{K}$.

\begin{tabular}{|c|c|c|c|c|c|c|c|c|}
\hline \multicolumn{9}{|c|}{$\mathrm{T}\left[{ }^{\circ} \mathrm{K}\right]$} \\
\hline$N_{\mathrm{Bi}}$ & 1023 & 1073 & 1123 & 1173 & 1200 & 1223 & 1273 & 1323 \\
\hline 0.1 & 0.205 & 0.195 & 0.186 & 0.178 & 0.174 & 0.172 & 0.165 & 0.160 \\
\hline 0.2 & 0.338 & 0.328 & 0.319 & 0.310 & 0.306 & 0.304 & 0.297 & 0.291 \\
\hline 0.3 & 0.518 & 0.491 & 0.470 & 0.450 & 0.442 & 0.434 & 0.4119 & 0.405 \\
\hline 0.4 & 0.548 & 0.533 & 0.521 & 0.508 & 0.503 & 0.499 & 0.489 & 0.480 \\
\hline 0.5 & 0.727 & 0.689 & 0.657 & 0.627 & 0.613 & 0.603 & 0.581 & 0.561 \\
\hline 0.6 & 0.749 & 0.730 & 0.714 & 0.696 & 0.690 & 0.684 & 0.671 & 0.659 \\
\hline 0.7 & 0.844 & 0.822 & 0.801 & 0.782 & 0.773 & 0.766 & 0.751 & 0.739 \\
\hline 0.8 & 0.897 & 0.885 & 0.874 & 0.862 & 0.858 & 0.852 & 0.844 & 0.836 \\
\hline 0.9 & 0.999 & 0.972 & 0.943 & 0.925 & 0.911 & 0.907 & 0.889 & 0.873 \\
\hline
\end{tabular}

Table 1.

Corrected $\mathrm{Bi}$ activities $a_{\mathrm{Bi}}$ as a function of $\mathrm{Bi}$ concentration and temperature.

\begin{tabular}{lllllllll}
\hline \multicolumn{2}{c}{$\mathrm{T}\left[{ }^{\circ} \mathrm{K}\right]$} & & & & & & & \\
$N_{\text {Sn }}$ & 1023 & 1073 & 1123 & 1173 & 1200 & 1223 & 1273 & 1323 \\
\hline 0.1 & 0.169 & 0.178 & 0.184 & 0.206 & 0.185 & 0.207 & 0.072 & 0.143 \\
0.2 & 0.365 & 0.341 & 0.317 & 0.308 & 0.322 & 0.293 & 0.282 & 0.276 \\
0.3 & 0.440 & 0.427 & 0.416 & 0.418 & 0.429 & 0.404 & 0.403 & 0.392 \\
0.4 & 0.552 & 0.529 & 0.509 & 0.514 & 0.515 & 0.498 & 0.498 & 0.486 \\
0.5 & 0.579 & 0.569 & 0.568 & 0.599 & 0.592 & 0.585 & 0.583 & 0.600 \\
0.6 & 0.724 & 0.711 & 0.688 & 0.691 & 0.666 & 0.667 & 0.669 & 0.668 \\
0.7 & 0.753 & 0.740 & 0.730 & 0.732 & 0.741 & 0.708 & 0.732 & 0.743 \\
0.8 & 0.849 & 0.848 & 0.837 & 0.827 & 0.820 & 0.841 & 0.832 & 0.825 \\
0.9 & 0.909 & 0.901 & 0.901 & 0.906 & 0.905 & 0.905 & 0.913 & 0.916 \\
\hline
\end{tabular}

Table 2.

Sn activities $a_{\mathrm{Sn}}$ as a function of Sn concentration and temperature. 

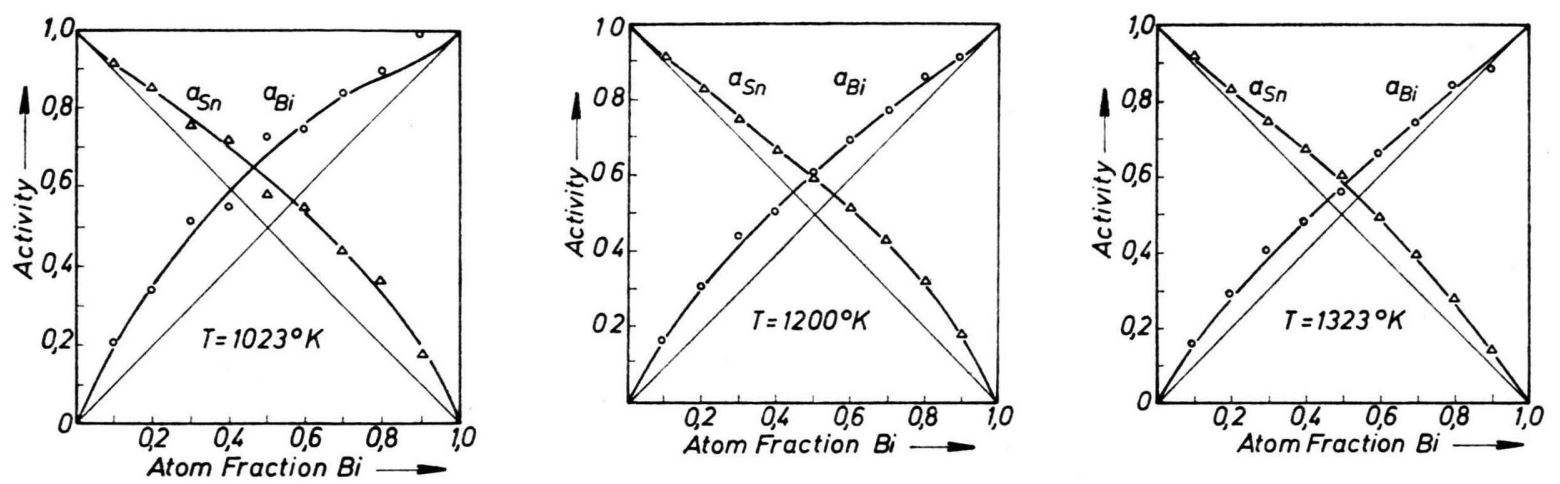

Fig. 5. Bi-Sn System: Activities $a_{\mathrm{Bi}}$ and $a_{\mathrm{Sn}}$ at a) $1023^{\circ} \mathrm{K}$; b) $1200^{\circ} \mathrm{K}$; c) $1323^{\circ} \mathrm{K}$.

Table 3. Bi-Sn System: Partial and integral thermodynamic functions of mixture in cal/mole, at the temperatures of $1123^{\circ} \mathrm{K}$ and $1173^{\circ} \mathrm{K}$

\begin{tabular}{lrrlrrr}
\hline \multicolumn{3}{l}{ Temperature $1123^{\circ} \mathrm{K}$} & \multicolumn{5}{c}{$1173^{\circ} \mathrm{K}$} \\
$N_{\mathrm{Bi}}$ & \multicolumn{1}{c}{$\mu_{\mathrm{B} 1}^{\mathrm{E}}$} & \multicolumn{1}{c}{$\mu_{\mathrm{Sn}}^{\mathrm{E}}$} & $\Delta G \mathrm{E}$ & \multicolumn{1}{c}{$\mu_{\mathrm{B} 1}^{\mathrm{E}}$} & \multicolumn{1}{c}{$\mu_{\mathrm{Sn}}^{\mathrm{E}}$} & $\Delta G \mathrm{E}$ \\
\hline 0.1 & 1386 & 2 & 141 & 1345 & 14 & 147 \\
0.2 & 1042 & 102 & 290 & 1022 & 78 & 267 \\
0.3 & 1002 & 105 & 374 & 947 & 103 & 356 \\
0.4 & 589 & 306 & 419 & 557 & 328 & 420 \\
0.5 & 609 & 283 & 446 & 528 & 390 & 429 \\
0.6 & 388 & 540 & 449 & 346 & 585 & 442 \\
0.7 & 302 & 732 & 431 & 258 & 771 & 412 \\
0.8 & 198 & 1024 & 363 & 175 & 1009 & 342 \\
0.9 & 115 & 1366 & 240 & 62 & 1683 & 224 \\
\hline
\end{tabular}

Table 4. Bi-Sn System: Partial and integral molar heats of mixing in $\mathrm{cal} / \mathrm{mole}$.

\begin{tabular}{lrrr}
\hline$N_{\mathrm{Bi}}$ & $\Delta H_{\mathrm{Bi}}$ & $\Delta H_{\mathrm{Sn}}$ & \multicolumn{1}{c}{$\Delta H$} \\
\hline 0.1 & 2484 & 26 & 272 \\
0.2 & 2162 & 199 & 592 \\
0.3 & 2212 & 324 & 890 \\
0.4 & 2037 & 473 & 1099 \\
0.5 & 1765 & 523 & 1144 \\
0.6 & 1391 & 920 & 1203 \\
0.7 & 1043 & 1639 & 1222 \\
0.8 & 596 & 2311 & 939 \\
0.9 & 372 & 3478 & 683 \\
\hline
\end{tabular}

The significant positive deviation of the uncorrected values of $a^{*}$ compared with those obtained by the integration method is caused by the fragmentation discussed in a previous section.

From both curves of $a_{\mathrm{Bi}}^{+}$and $a_{\mathrm{Bi}}$ the correction factor $K_{\mathrm{Bi}}$ was now calculated for different concentrations using Equation (5). The value of $K_{\mathrm{Bi}}$ was found to be independent of concentration and its magnitude was $0.43 \pm 0.05$. This means according to Eqs. (6) and (7) that for pure bismuth about

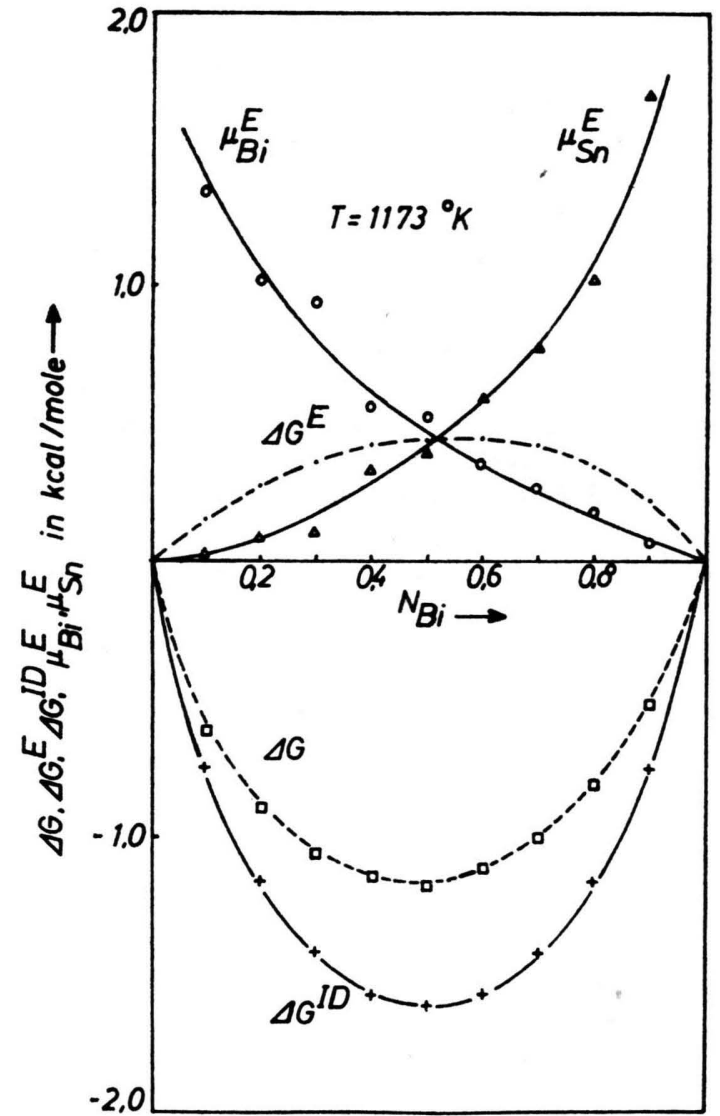

Fig. 6. Bi-Sn System: Excess Gibbs energy $\Delta G^{\mathrm{E}}$, excess chemical potentials $\mu_{\mathrm{B} 1}^{\mathrm{E}}$ and $\mu_{\mathrm{sn}}^{\mathrm{E}}$, ideal Gibbs energy $\Delta G \mathrm{ID}$ and total Gibbs energy $\Delta G$ at $1173^{\circ} \mathrm{K}$.

$70 \%$ of the measured monomeric ion current derives from ionization of the monomers effusing directly from the Knudsen cell and that the other $30 \%$ of this current is produced by fragmentation in the ionization region. 
Assuming that in the temperature region between $1023{ }^{\circ} \mathrm{K}$ and $1323^{\circ} \mathrm{K}$ there is a considerably smaller temperature dependence of the $K_{\mathrm{Bi}}$ values than of the activity which is to be evaluated, each of the values obtained by the monomer-dimer method was corrected using the factor $K_{\mathrm{Bi}}=0.43\left(1200^{\circ} \mathrm{K}\right)$ and is listed in Table 1 . The activities of tin were calculated using Duhem-Margule's equation and are listed in Table 2.

Figure 5 shows the activities of bismuth and tin vs. concentration for the three temperatures of 1023,1200 , and $1323^{\circ} \mathrm{K}$. Compared with the values reported by Hultgren et al. ${ }^{5}$ for a temperature of $608{ }^{\circ} \mathrm{K}$, agreement is found in the tendency to segregation and also in the shape of the activity curves. An extrapolation of the values of the present work to the temperature of $600{ }^{\circ} \mathrm{K}$, which, however, can only give rough qualitative information because of the great temperature difference, leads to activities which differ considerably from those of Hultgren et al.

Using the values of $a_{\mathrm{Bi}}$ and $a_{\mathrm{Sn}}$ it was possible to calculate some partial and integral functions of mixing. The excess Gibbs energy $\Delta G^{\mathrm{E}}$ is given by Equation (11). The values of $\Delta G^{\mathrm{E}}$ as well as those of the excess chemical potentials $\mu_{\mathrm{Bi}}^{\mathrm{E}}$ and $\mu_{\mathrm{Sn}}^{\mathrm{E}}$ are listed in Table 3 for the temperature of $1123^{\circ} \mathrm{K}$ and $1173^{\circ} \mathrm{K}$. Figure 6 shows the curves of $\Delta G^{\mathrm{E}}$, $\mu_{\mathrm{Bi}}^{\mathrm{E}}, \mu_{\mathrm{Sn}}^{\mathrm{E}}$, and, additionally, the curves of the ideal

1 I. Berkowitz and W. A. Chupka, Trans. N. Y. Acad. Sci. 79, 1075 [1950].

2 G. R. Belton and R. I. Fruehan, Met. Trans. 2, 291 [1971].

${ }^{3}$ G. R. Belton and R. I. Fruehan, J. Phys. Chem. 71, 1403 [1967].

4 D. Cocke, at present Fritz Haber Institut, Berlin, formerly Texas A \& M University, performed these modifications in a commendable way.

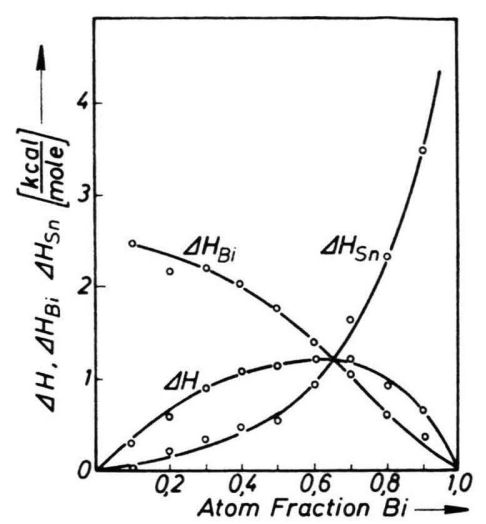

Fig. 7. Bi-Sn System: Partial molar heats of mixing $\Delta H_{\mathrm{Sn}}$ and $\Delta H_{\mathrm{Bi}}$ and integral molar heat of mixing $\Delta H$.

Gibbs energy $\Delta G^{\mathrm{ID}}$ and of $\Delta G=\Delta G^{\mathrm{ID}}+\Delta G^{\mathrm{E}}$ for $T=1173 \mathrm{~K}$.

The partial molar heats of mixing $\Delta H_{\mathrm{Bi}}$ and $\Delta H_{\mathrm{Sn}}$ and the integral molar heat of mixing $\Delta H$ were calculated from the temperature dependence of the activities using Eq. (10) and are plotted in Figure 7 .

In general, the values obtained in the present work show, that there are relatively strong forces of interaction between atoms of the same kind in the $\mathrm{Bi}-\mathrm{Sn}$ system, i. e., a tendency to segregation.

5 R. Hultgren, R. L. Orr, P. D. Anderson, and K. K. Kelley, Selected Values of Thermodynamic Properties of Metals and Alloys, J. Wiley and Sons, New York 1963.

6 I. L. Margrave, The Characterization of High-Temperature Vapors, Wiley and Sons, New York 1967.

7 K. A. Gingerich, A. Desideri, and D. L. Cocke, J. Chem. Phys. 62, No. 2 [1975]. 